\title{
"LANÇANDO LUZ SOBRE A COISA PÚBLICA": UMA ANÁLISE DO DISCURSO DO SETOR PRIVADO SOBRE O REGIME DE COLABORAÇÃO ${ }^{1}$
}

\author{
GEORGE SOUZA DE MELO ${ }^{2}$ \\ JÉSSICA DO NASCIMENTO SILVA ${ }^{3}$ \\ DIEGO JOSÉ DE SENA ${ }^{4}$ \\ ERIKA FARIAS NOGUEIRA DA SILVA ${ }^{5}$
}

\begin{abstract}
Programa de Pós-Graduação em Educação (PPGE)
Centro de Educação - Universidade Federal de Pernambuco

Av. da Arquitetura, s/n - Cidade Universitária - 50740-550 - Recife - PE - Brasil

georgedemelosdb@gmail.com, jessicanascimento1971@hotmail.com, diego jsena@hotmail.com, erikafariasl5@hotmail.com
\end{abstract}

\begin{abstract}
Resumo. O presente texto dedica-se a perceber como a Análise do Discurso, enquanto escolha teórico-metodológica de estudo, aponta a discursividade que se desenvolve, se ressignifica e produz sentidos que são construidos nos espaços do discurso por meio da cena da enunciação, cena englobante e cena genérica. Na opção pelo corpus, selecionamos a plataforma de apresentação do Movimento Colabora Educação que atua, segundo o que dizem, 'lançando luz sobre o entendimento dos entes federados sobre o regime de colaboração'. A partir da constituição do corpus, justificam-se os usos de categorias (interdiscurso, ethos e cenografia) propostas por Dominique Maingueneau, tendo em vista que o discurso selecionado forja cenas produzidas sobre a ideia de educação de qualidade. $O$ texto analisado possibilitou observar a construção de uma imagem do movimento caracterizada enquanto técnica, bem-sucedida e empresarial. É, então, por meio de um discurso marcadamente publicitário e sob forte influência de ideias do setor econômico privado, que o Movimento Colabora Educação apresenta e difunde a sua noção de regime de colaboração e de educação de qualidade.
\end{abstract}

Palavras-chave: discurso; regime de colaboração; educação de qualidade.

\begin{abstract}
This paper is dedicated to perceiving how Discourse Analysis, as a theoretical-methodological choice of study, points to the discursiveness that develops itself, resignifies itself and produces meanings that are constructed in the spaces of discourse through the enunciation scene, an encompassing scene and generic scene. For the corpus, we selected the presentation
\end{abstract}

\footnotetext{
${ }^{1}$ Este artigo é resultado de um exercício realizado durante o curso de mestrado das/dos articulistas, que contou com o apoio financeiro da Capes e do CNPq.

${ }^{2}$ Doutorando em Educação pela Universidade Federal de Pernambuco.

${ }^{3}$ Mestranda em Educação pela Universidade Federal de Pernambuco.

${ }^{4}$ Mestrando em Educação pela UFPE. Professor da educação básica na Rede Municipal de Paulista - PE.

${ }^{5}$ Mestranda em Educação pela Universidade Federal de Pernambuco.
} 
platform of the Movimento Colabora Educação that operates, according to what they say, 'clarifying the understanding of the federated entities about the collaboration regime'. From the constitution of the corpus, the uses of categories (interdiscourse, ethos and scenography) proposed by Dominique Maingueneau are justified, considering that the selected discourse forges scenes produced on the idea of quality education. The analyzed text made it possible to observe the construction of an image of the movement characterized as technical, successful and corporate. It is, then, through a highly publicized discourse and under the strong influence of ideas from the private economic sector, that the Movimento Colabora Educação presents and disseminates its notion of collaboration regime and quality education.

Keywords: discourse; collaboration regime; quality education.

\section{ESBOÇANDO AS BASES DE UMA INVESTIGAÇÃO}

O nosso objeto principal de análise é o discurso de apresentação do Movimento Colabora Educação (MCE), presente no site do próprio movimento. Entendendo discurso como uma unidade de significação que vai além da frase e, seguindo as indicações de Burity (2014) e Laclau (1995) que o apresentam como um sistema de regras de produção de sentido, trazemos esse conceito como um auxílio fundamental para o entendimento do quanto a questão do sentido é importante na reflexão sobre as ações políticas e sociais. $\mathrm{O}$ sentido, assim, existe a partir dos significados que são produzidos constantemente pelo esforço de se dizer algo sobre o real. Porém, isso não quer dizer que a enunciação é um reflexo do real. Ao contrário, quando dizemos "sobre o real", estamos querendo evidenciar: "dar-lhe sentido, inseri-lo nos jogos de linguagem e sistemas de classificação que permitem que ele seja definido desta ou daquela forma" (LOPES E MACEDO, 2011, p. 197).

Dessa forma, a realidade se positiva a partir dos atos enunciativos que articulam significados diversos, como que num esforço constante de estancamento do fluxo de significações possíveis sobre tudo, que é infinito e que não cessa de se movimentar a partir de qualquer ato de fala. Esses estancamentos de significados de que falamos são como que pontos nodais de sentido (para se aproximar da noção laclauniana), a partir dos quais se é possível conferir alguma inteligibilidade às realidades. Assim sendo, se é desmontada toda consideração que pressupunha a realidade como algo externo que precisa ser acessado e/ou desvendado, de alguma forma, pelas análises críticas e discursivas. E se é aceito que as próprias análises e investidas crítico-discursivas são, elas mesmas, constituidoras do real e fundamentais para os seus mais improváveis deslocamentos e reproduções.

Nesse sentido, quando mobilizamos aqui um discurso de/sobre uma instituição que se coloca como ligada diretamente ao trabalho educacional, certamente, estamos, antes de tudo, considerando as possíveis articulações investidas por esse discurso com vistas na produção da educação de um modo bem específico que deve entrar em disputa pela hegemonia nos planos políticos e sociais. Ou seja, nos preocupamos, desde antes, 
em analisar como e que "educação" 6 é produzida a partir das enunciações do Movimento Colabora Educação, e não se esta instituição está, de fato, colaborando com "a" educação. Pois, entendemos que "a educação", como algo de uma realidade estática e ontológica a ser buscada em algum lugar, não existe.

Reconhecemos que as fronteiras que, aparentemente, pela epistemologia clássica, nos separavam em pesquisadoras/es e objeto, nessa perspectiva discursiva, já não se sustentam. E passamos a afirmar que, na verdade, vivemos sempre nas margens dessas fronteiras, nos constituindo mutuamente em pesquisadoras/es, objetos e fenômenos. No entanto, isso nos ajuda a reiterar que não nos preocupa tratar o discurso que iremos analisar como um "objeto", conforme citamos acima. Tal posição não se distancia da produção discursiva do real, pois entendemos que a ontologia dos fenômenos é produzida a partir das mobilizações discursivas que são investidas para dar conta, mesmo que precariamente, dos relatos sobre as coisas e o mundo. Dessa forma, ao elegermos a apresentação do Movimento Colabora Educação como passível de análise crítica, estamos cientes de que constituímos um fenômeno de pesquisa que precisa "ser elaborado assumindo seu caráter precário e disputado, como objeto, [e que] sua estrutura e suas dinâmicas somente ganham sentido no contexto de suas relações com os diversos elementos e processos que se desdobram nos campos discursivos dos quais emergem" (OLIVEIRA, 2018, p. 185).

Desde já, vale ressaltar que a noção de campo discursivo remete a "um espaço no qual se confrontam os diversos posicionamentos políticos [e que, por isso,] não são estruturas estáticas, já que são constantemente submetidos a uma lógica de concorrência em que cada [gênero] visa modificar as relações de força em seu benefício" (MAINGUENEAU, 2015, p. 66; 68). Nesse sentido, como será visto na citação abaixo, identificamos que o discurso que apresenta o Movimento Colabora Educação o coloca num campo discursivo de disputa em torno do que seja a governança da educação no Brasil e, consequentemente, de como devem se pautar as políticas públicas de colaboração nesse setor. Eis, portanto, o texto de apresentação do movimento, disponibilizado pelo seu site:

O Movimento Colabora Educação surge com o objetivo de fortalecer a governança e as práticas colaborativas entre os entes federativos no âmbito das políticas públicas de educação. Sua atuação parte do entendimento de que o desenvolvimento desses dois pilares do regime de colaboração é condição necessária para a melhoria da aprendizagem e promoção da equidade. Nascido como uma Mesa Temática no âmbito do Conselho Consultivo da Sociedade Civil do Banco Interamericano de Desenvolvimento (BID) no Brasil, o Colabora conta com os seguintes membros: Instituto Natura, Instituto Unibanco, Fundação Itaú Social, Movimento Todos pela Educação, Fundação Lemann, Instituto Positivo, Instituto Ayrton Senna e Instituto Conceição Moura, além do próprio BID. (MOVIMENTO COLABORA EDUCAÇÃO, 2018?) ${ }^{7}$

\footnotetext{
${ }^{6}$ À moda de Butler (1998), as aspas são utilizadas neste momento, como em outros no decorrer deste artigo, para dispor que essas palavras estão colocadas sob questionamento, ou seja, que estão sendo desnaturalizadas de seu sentido tradicional e estão sendo entendidas como lugares de disputa.

${ }^{7}$ A referência eletrônica completa se encontra no final deste artigo.
} 
Como já dissemos, é claro que o discurso apresentado pelo MCE não representa a determinação de verdade sobre o que seja aquilo que está disputando no campo discursivo acerca da educação e sua governança. Porém, ampliando nossa análise para além desse texto apresentado, tentaremos apresentar qual(is) seja(am) a(s) possível(eis) representação(ções) que esse discurso enseja como passível de articulação hegemônica a determinar as políticas públicas que nortearão os caminhos de colaboração no sistema educativo brasileiro.

Para tanto, lançaremos mão a partir de agora de algumas outras categorias de análise que julgamos serem fundamentais no fortalecimento desse processo que intentamos realizar acerca da compreensão discursiva do MCE. Como deixamos claro desde o início que se trata de um discurso próprio de um movimento, ou seja, que tem uma localização bem específica, cabe dizer que estamos trabalhando com uma unidade tópica de discurso (MAINGUENEAU, 2015). Como uma unidade deste tipo, nos cabe agora especificá-la a partir da apresentação contextual e física que escolhemos; tentar dissertar sobre como ela é produzida, inserida e classificada nos moldes em que se apresenta, e quais são os seus possíveis efeitos e/ou, pelo menos, o que julgamos, a partir da análise, ser suas intencionalidades em termos de imagens/produção do real. Nesse sentido, na seção seguinte, trataremos de considerações mais históricas e contextuais no que se refere ao Regime de Colaboração e ao próprio Movimento Colabora para, posteriormente, passarmos à análise do artefato discursivo propriamente dita. Para tal, as noções de gênero do discurso, cenas da enunciação e ethos, a partir de Maingueneau, nos parecem adequadas para entendermos quais e como são produzidas as articulações discursivas do MCE, no que diz respeito à sua apresentação através de seu site oficial.

\section{REGIME DE COLABORAÇÃO: LÓCUS DE ATUAÇÃO}

O intuito desse tópico é apresentar o campo político em que o Movimento Colabora Educação atua. Como veremos ao longo do estudo, todos os dispositivos que o Movimento Colabora Educação apresenta em sua plataforma digital convergem para o convencimento de que esta entidade é a que possui os requisitos necessários para gestar os arranjos colaborativos entre as diferentes esferas administrativas do governo, estando também preparada para articular parcerias entre sociedade civil e poder público.

\section{ALGUMAS CONSIDERAÇÕES SOBRE A POLÍTICA DO REGIME DE COLABORAÇÃO E O SISTEMA NACIONAL DE EDUCAÇÃO}

O processo de redemocratização do estado brasileiro, que acontece após o regime ditatorial cívico-militar, traz consigo avanços nas demandas sociais até então dormentes. A exemplo disso, a Constituição Federal de 1988 eleva os municípios à condição de Ente Federativo. Na prática, os estados e municípios tornam-se supremacias estatais e, ao Governo Federal (União), cabe a administração das pautas em comum aos entes federativos e o papel de representar a Soberania Nacional ante os demais países do globo.

Estados e Municípios abrem mão de suas respectivas soberanias, porém sem perder suas autonomias, conforme aponta Saviani (2011, p. 2): "Aquilo que caracteriza a federação é a unidade de vários estados que, preservando suas respectivas identidades, intencionalmente se articulam tendo em vista assegurar interesses e necessidades 
comuns." Com isso, estados e municípios podem redigir suas leis orgânicas de acordo com suas especificidades, desde que não firam a Constituição Federal.

Dado o vasto território nacional e as dificuldades pertinentes à sua administração, foi proposto um acordo entre União, Estados e Municípios em torno de uma agenda em comum, que se caracterizou como Regime de Colaboração. O Regime de Colaboração aparece no texto da Carta Magna de 1988 nos Artigos 1º; 18; 23; 29; 30 e 211. No âmbito da educação, propõe uma ação conjunta entre Governo Federal, Distrito Federal, Estados e Municípios na construção de um sistema pautado na troca de experiências e de um equilíbrio fiscal através do financiamento, uma vez que determinadas regiões conseguem captar mais impostos que outras, a exemplo da diferença de arrecadação entre Norte e Sudeste. Em educação, o equilíbrio orçamentário possibilitaria o fortalecimento de uma política pública de estado para o desenvolvimento educacional em todo o território nacional, com vistas, tanto na qualidade total, como na qualidade social da educação. Ainda segundo Saviani (2011), mesmo com as garantias de autonomia dos entes, se faz necessário um órgão irradiador que consiga equilibrar os abismos educacionais:

a melhor forma de fortalecer as instâncias locais não é, necessariamente, conferir-lhes autonomia deixando-as, de certo modo, à própria sorte. Na verdade, a melhor maneira de respeitar a diversidade dos diferentes locais e regiões é articulá-los no todo, e não isolá-los. Isso porque o isolamento tende a fazer degenerar a diversidade em desigualdade, cristalizando-a pela manutenção das deficiências locais (p. 5).

O financiamento fica a cargo das três instâncias, a partir do Fundo de Manutenção e Desenvolvimento da Educação Básica e de Valorização dos Profissionais da Educação - FUNDEB, cuja maior parte dos recursos provém de estados e municípios, ficando a União com a incumbência de complementação orçamentária. O novo plano do FUNDEB, a ser desenvolvido para 2020 deverá passar por uma atualização para abarcar também o regime colaborativo.

Esse caminho nos leva ao debate em torno do Sistema Nacional de Educação (SNE), uma exigência que reverbera desde o Movimento dos Pioneiros da Educação Nova, na primeira metade do século XX e que ganha força durante o debate do novo Plano Nacional da Educação 2014-2024 (PNE). Foi no decorrer da Conferência Nacional de Educação 2014 (CONAE) que o debate acerca de um sistema de articulação entre os entes federados e a sociedade civil ganhou novo fôlego.

A execução de um Sistema Nacional de Educação proporcionaria a troca de experiências exitosas entre os membros da Federação, poupando assim esforços para o enfrentamento de problemas educativos comuns à educação brasileira, respeitando logicamente as particularidades de cada estado e município; dessa forma, o SNE vai além do equilíbrio do financiamento da educação.

Abicalil (2014, p. 3 apud Cury, 2009, p. 22) apresenta os pontos necessários à construção do SNE: 
Assim, o pacto federativo dispõe, na educação escolar, a coexistência coordenada e descentralizada de sistemas de ensino sob o regime de colaboração recíproca:

- com unidade: art. $6^{\circ}$ e art. 205 da CF/88;

- com divisão de competências e responsabilidades;

- com a diversidade de campos administrativos; com diversidade de níveis de educação escolar;

- com assinalação de recursos vinculados.

Abicalil (2014, p. 2) ainda reitera a necessidade da jurisdição por meio de lei complementar para criação do SNE e concretização do PNE:

O debate em torno do PNE trouxe matizes importantes originadas na própria Conferência Nacional de Educação (CONAE) e nas exigências de novos ordenamentos jurídicos-constitucionais, especialmente derivados da Emenda Constitucional no 59/2009 (BRASIL, 2009). A intrínseca relação entre o PNE e a articulação do Sistema Nacional de Educação (SNE) ganhou estatura constitucional inédita, exigindo a necessária regulação atualizada da cooperação federativa e da colaboração entre sistemas.

Apesar do debate em torno da criação do SNE apresentar-se favorável tanto para os conservadores quanto para os progressistas, o obstáculo maior para sua formalização está na inexistência de um projeto de lei que judicialize sua materialização. É a ausência de um aparato legal o que torna frágil também a concretização de um Regime de Colaboração em nível nacional. Uma lei complementar poderia jogar luzes frente aos desafios e demandas que esse tipo de projeto necessita, tais como todas as regras referentes à manutenção do fundo financeiro e a criação de um termo que garanta adesão total dos municípios e estados do território nacional em torno dessa agenda colaborativa, evitando assim fragmentação e enfraquecimento do SNE.

\section{O SETOR PRIVADO E O REGIME DE COLABORAÇÃO}

Nos debates do Conselho Nacional de Educação (CNE) apresentam-se disputas acerca do regime de colaboração e consequentemente da criação do SNE. A iniciativa privada, presente na edição do CNE de 2012, representada pelo movimento empresarial Todos Pela Educação (TPE) apresentou, na época, a proposta dos chamados Arranjos de Desenvolvimento Educacional (ADE), no qual um novo formato de regime de colaboração é proposto, dessa vez com parcerias público-privadas assumindo a dianteira das relações construídas horizontalmente entre os entes federados. Argollo e Motta (2015, p. 45) completam:

Os ADE demarcam elementos determinantes no processo de crescente busca de hegemonia dos empresários organizados e na política de redefinição dos métodos de gestão das instituições públicas educacionais municipais, inserindo uma reconfiguração do regime de colaboração entre os entes federados e na organização dos sistemas de ensino.

A inclusão da agenda da iniciativa privada fez com que o Ministério da Educação criasse o Índice de Desenvolvimento da Educação Básica (IDEB) e o Plano de Ações 
Articuladas (PAR), que possuem uma perspectiva de educação de qualidade, construídos a partir de processos economicistas de educação, baseados em competitividade entre alunos, escolas da mesma rede e de redes circunvizinhas, produtividade do corpo docente e meritocracia. Eis a primeira atuação dos Arranjos de Desenvolvimento da Educação defendidos pelas empresas que compõem o movimento TPE e que, em sua maioria (incluindo o próprio TPE), compõem também as instituições formadoras e mantenedoras do Movimento Colabora Educação: uma educação baseada em resultados, conforme destacam Argollo e Motta (2015, p. 48).

O processo de regulamentação do regime de colaboração de novo tipo vem se apresentando como condição a priori para o desenvolvimento da suposta 'qualidade' de ensino na educação básica e se constituindo por meio da normatização dos ADE e da execução de instrumentos de monitoramento e de controle da relação de ensino-aprendizagem nas instituições escolares municipais.

Um exemplo é o que ocorre no estado do Ceará, o regime de colaboração que acontece entre os municípios desse estado limita-se à troca de experiências para elevar o ranking das escolas, contando com a atuação das empresas que compõem o TPE na implementação de programas de formação continuada de professores e material didático para os alunos.

Argollo e Motta (2015, p. 49) apresentam o pensamento de Ramos (2010) que sintetiza essas articulações da seguinte forma:

Ao definir os $\mathrm{ADE}$ como uma metodologia de gestão estratégica e promotora da 'qualidade' da educação básica no âmbito local, o TPE, em articulação com setores do MEC e do CNE, propõe reorganizar o ensino fundamental em formato de rede entre um grupo de municípios, com proximidade geográfica e com características sociais e econômicas semelhantes, e estimular que troquem 'experiências' na perspectiva do voluntariado intermunicipal para alavancar os indicadores educacionais e, com isso, impulsionar o desenvolvimento local, em uma ação conjunta com o Ministério da Educação (MEC) e outros parceiros.

Fica claro, portanto, que a forma de atuação dos ADE está intimamente ligada aos direcionamentos dos órgãos oficiais do governo, encampando uma agenda de uma educação voltada para resultados, que agradaria ao mercado, ao mesmo tempo que esvazia a construção de uma educação que se proponha como produtora e difusora de conhecimento. $\mathrm{O}$ regime de colaboração e a construção do SNE ficam circunscritos à adaptação de experiências exitosas nos entes federativos que ainda não alcançaram os índices que o TPE, o Movimento Colabora Educação e as outras estruturas da iniciativa privada julgam tradutores de uma educação de qualidade.

\section{MOVIMENTO COLABORA EDUCAÇÃO E A CONSTRUÇÃO DO OUTRO ENFRAQUECIDO}

A partir das categorias propostas por Maingueneau (2008; 2013; 2015), o discurso publicitário presente no site do Movimento Colabora Educação, tomado como corpus em 
nossa análise, evidencia que esse gênero do discurso é, de fato, uma espécie de máxima na apresentação da ideia de qualidade na educação para esse grupo. $\mathrm{O}$ site, enquanto gênero discursivo, utiliza-se de aspectos visuais que atraem e anunciam algo que se projeta no desejo de aceitação do outro. O discurso do $\mathrm{MCE}$, a partir da relação interdiscursiva com a qualidade da educação, apresenta dados acerca desta para enunciar efeitos de verdade. Através da plataforma de apresentação tomada enquanto discurso é possível perceber como se revela o ethos, que entendemos ser a produção da ideia de educação a partir das enunciações do MCE, e como ele se constitui na cenografia.

O texto analisado possibilitou observar a construção de uma imagem de si caracterizada enquanto técnica, bem-sucedida e empresarial. O sujeito enunciador (MCE) apresenta a importância da educação, sem se comprometer diretamente com o seu discurso, ou seja, seu papel é de benevolência, pois estamos tratando de uma iniciativa articulada por empresas que não atuam diretamente na área da educação, mas que apresentam ao co-enunciador (gestores do setor público) a saída para falta de qualidade na educação, dentro da perspectiva empresarial.

De acordo com Flavio Sabino Pinto (2015), revela-se no corpus o interdiscurso como um transpassado de variados discursos convencionados. Os discursos do MCE são elaborados pela incorporação do simulacro do outro. Assim, torna-se possível comprovar, por meio das pistas linguísticas e imagéticas "que todo discurso traz no seu interior o outro, pois a interdiscursividade é inerente à linguagem” (PINTO, 2015, p. 240).

Para entender e analisar a construção discursiva da plataforma de apresentação do Movimento Colabora Educação, faz-se necessário caracterizar o cenário político que possibilita a criação dessa estrutura, pois, como apresentado anteriormente, o MCE é uma iniciativa do setor privado, com empresas de diferentes atuações no mercado, que busca lançar luz sobre o entendimento dos entes federados sobre o regime de colaboração ${ }^{8}$. A opção pelo discurso na plataforma de apresentação do MCE surge a partir de uma palestra de seus representantes em uma instituição do setor público, onde a afirmação citada acima foi proferida, com um modo de apresentação do MCE reunindo estratégias de convencimento e encanto quase impossíveis de reação. Compreendendo que esse discurso se desenvolve a partir de um amplo cenário, a fim de conquistar a adesão do coenunciador com a percepção da cena enunciativa que o legitima, seguimos nossa análise.

Para caracterizar o cenário político-educacional que possibilitou a expansão e protagonismo da iniciativa privada, pode-se inicialmente afirmar que os governos petistas (2003-2016) foram caracterizados como um governo de conciliação de classes. Salvo algumas especificidades do período em que Luís Inácio Lula da Silva governou (20032010) e do período em que Dilma Vana Rousseff governou (2011-2016), as políticas para educação dos governos petistas sempre mantiveram um braço de atuação na educação pública, mas garantindo o outro braço e as pernas na iniciativa privada ${ }^{9}$. Não cabe no

\footnotetext{
${ }^{8}$ Esta afirmação foi feita por um dos representantes do MCE durante a $3^{\text {a }}$ edição do Escola de Inovação e Políticas Públicas Debates, cujo tema foi “O Regime de Colaboração e seus Desafios”, organizada pela Fundação Joaquim Nabuco (FUNDAJ), em Recife/PE, e que contou com a participação de dois dos autores deste texto. Essa experiência é um pouco mais relatada nas considerações finais deste trabalho.

${ }^{9}$ Recomenda-se a leitura do texto disponível no site Esquerda Diário intitulado: Os limites das políticas de Lula e Dilma no Ensino Superior e na Educação Profissional, de autoria de Mauro Sala, publicado no dia
} 
presente texto uma análise mais aprofundada a respeito das circunstâncias que levaram a esse modo de governar, mas é significativo entender que esse protagonismo dado ao setor privado, por exemplo, foi responsável pela criação do maior monopólio da educação no mundo.

Diante da constatação de que o setor privado teve sua maior ampliação, no que se refere à educação, no período apresentado, o discurso político educacional apresenta-se enquanto cena englobante, que é equivalente ao tipo de discurso. Maingueneau (2015) aponta a dificuldade em categorizar o tipo de discurso, porém a partir de sua definição enquanto função social é possível traçar um caminho. Deste modo, define que as funções sociais estão relacionadas às esferas da sociedade em que as falas circulam. Podemos destacar, por exemplo: discurso publicitário, discurso literário e discurso político. Ao tomar contato com um texto, os indivíduos devem ter a capacidade de situar-se em um desses discursos, chamados então de cenas englobantes.

Caracterizada a cena englobante, partiremos para a definição da cena genérica em nossa análise. Ao lançar mão de artifícios publicitários em sua linguagem de apresentação, o site do MCE é o principal gênero de divulgação do mesmo, apresentando na aba 'Quem somos' uma linguagem curta e objetiva. Em três parágrafos são destacados o objetivo, sua atuação e quem são os membros apoiadores do MCE (vale destacar que esse é o maior parágrafo da apresentação). Ao lado do texto, uma imagem de pessoas formando um círculo, de mãos dadas, com diferentes cores, gêneros e credos, atrás dessas pessoas, instituições que lembram o cenário norte-americano. Podemos observar na imagem 1 os aspectos destacados.

Imagem 1. Apresentação do Movimento Colabora Educação.

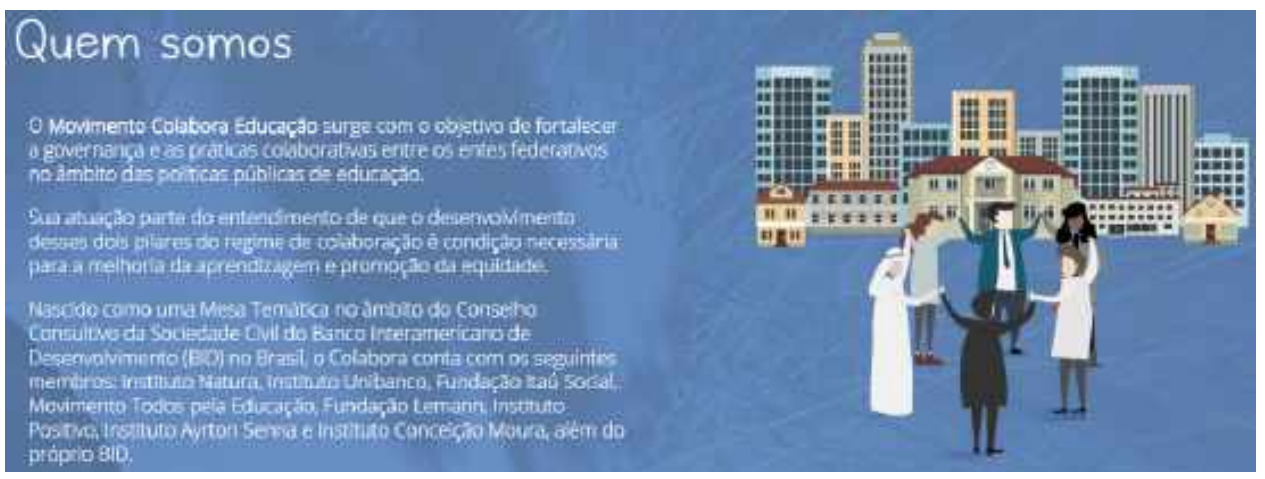

Ao pesquisar outras redes do MCE através de links disponíveis no site, observamos que os mesmos estavam inativos, mantendo o visitante na página inicial da plataforma. Pesquisando, à parte, identificamos a página do Facebook e observamos aquilo que afirmamos anteriormente, pois na página da rede social há algumas imagens de atividades realizadas pelo MCE. Acreditamos que o site é a principal ferramenta de apresentação, pois além de sua plataforma dinâmica e visualmente atrativa, no evento em

28 de fevereiro de 2018. Disponível em: https://www.esquerdadiario.com.br/Os-limites-das-politicas-deLula-e-Dilma-no-Ensino-Superior-e-na-Educacao-Profissional. 
que estivemos presentes (citado em nota acima), o material utilizado para apresentar o movimento tinha a mesma linguagem visual, com cores e textos idênticos.

Ao definir a cena genérica, pode-se afirmar que essa equivale aos vários gêneros do discurso com os quais nos deparamos, deste modo definem os protocolos, as posições sociais que cada co-enunciador e enunciador assumirá, espaços e momentos que podem ser utilizados e o modo como lê-los. Assim, caracteriza-se como um dispositivo de comunicação capaz de alterá-la através de um conjunto de gêneros já presentes e conhecidos dos indivíduos. Para Maingueneau (2013), cada gênero ou subgênero de discurso define o papel de seus participantes, por exemplo, num panfleto de loja de roupas de bebê, convencionalmente teremos uma empresa dirigindo-se ${ }^{10}$ a mulheres que são mães; num curso, teremos um professor dirigindo-se a alunos entre outros exemplos.

Ao pensar a cenografia, Maingueneau (2015) evidencia que essa é a primeira instância que alcança o co-enunciador, anterior até mesmo à cena englobante e à cena genérica. De acordo com Pinto $(2015$, p. 244) "podemos afirmar que ela não vem pronta, como se já viesse construída no interior de um quadro cênico, mas é a enunciação que se desenvolve para legitimar a sua própria fala no discurso". Assim, a cenografia é parte integrante do que o discurso produz, sendo através de sinais detectáveis na materialidade do texto que a cenografia se apresenta. Ela não é construída previamente, mas paralelamente ao discurso, ou seja, é concebida de acordo com o que o discurso enuncia.

\section{Imagem 2. Texto escrito de apresentação do Movimento Colabora Educação.}

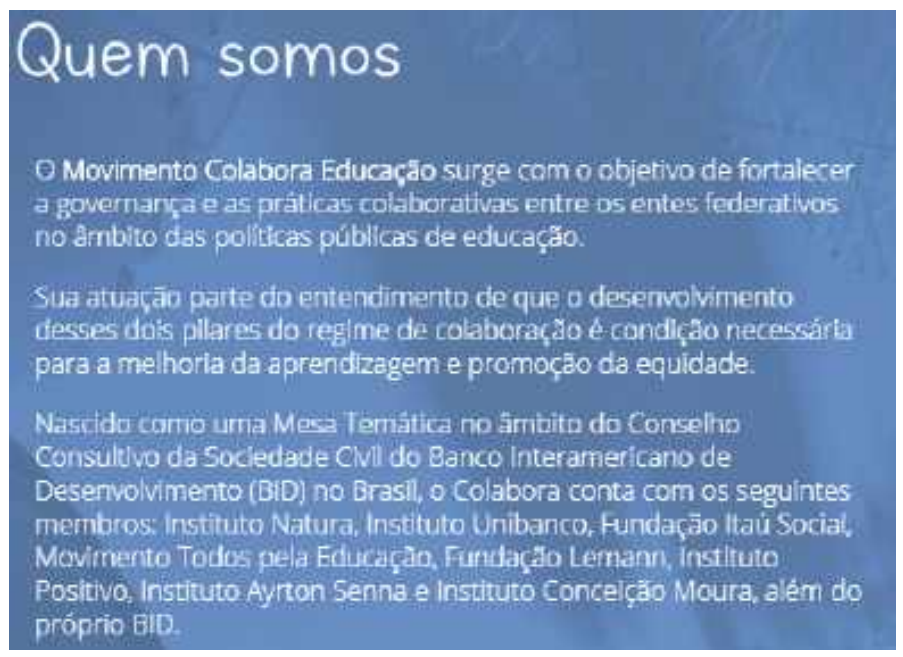

Enquanto cenografia, analisamos que o MCE apresenta em sua plataforma digital, sendo esse o suporte da sua mensagem, um discurso para gestores da educação (secretarias de educação, prefeituras, governos de estado, gestores e coordenadores educacionais). Ao analisar o texto escrito, observa-se que se trata de um texto visual,

\footnotetext{
${ }^{10}$ Dirigir-se, aqui, também pode ser entendido para além de uma consideração espacial em que a mensagem pretende alcançar algum determinado sujeito externo e/ou anterior ao discurso enunciado. Mais do que isso, se entende como sendo um processo que intenciona a produção dos próprios sujeitos a serem relacionados, estabelecendo sempre a necessidade da suposição de um ethos dos sujeitos nos atos mesmos de enunciação.
} 
utilizando fonte com aspectos de informalidade, objetividade ao caracterizar quem são, o que fazem e quem os apoia.

\section{Imagem 3. Imagem da apresentação do Movimento Colabora Educação.}

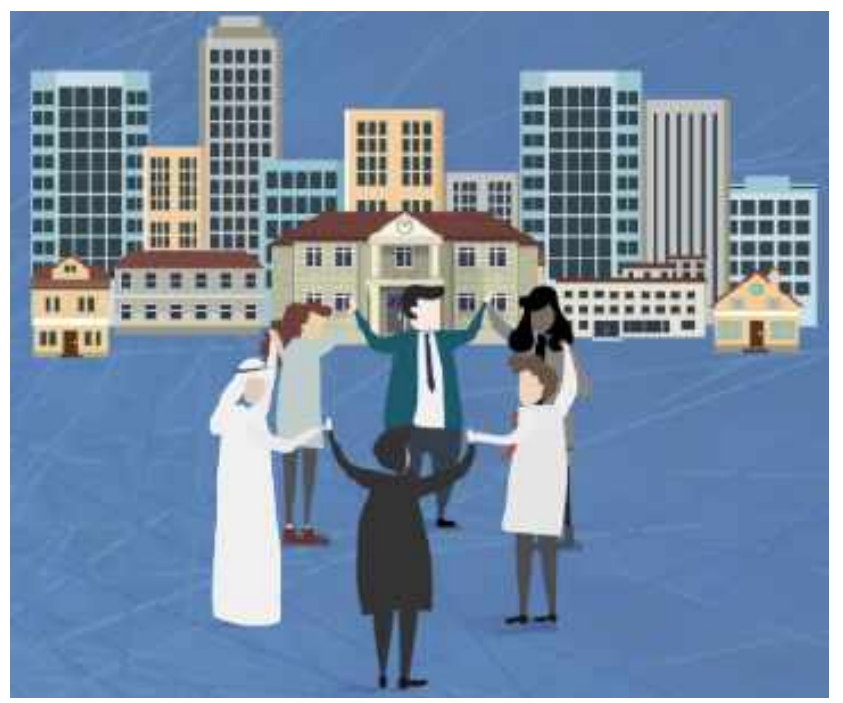

A imagem de pessoas de mãos dadas reforça a ideia de colaboração e esforço coletivo, os traços gráficos da imagem apresentam linguagem característica da área de administração e economia, setores com significativa proximidade ao setor privado. Outra importante observação acerca da imagem na apresentação é a diversidade presente nos personagens, em que temos a representação do gênero masculino e feminino, diferentes tonalidades de pele, a figura de um homem com trajes característicos do oriente médio, o que nos remete à diversidade cultural e religiosa. Tal diversidade torna a reforçar o discurso do coletivo. A pequena cidade atrás dos personagens nos remete a uma característica própria das instituições de ensino norte-americanas e de países da Europa.

Através da cenografia analisamos que a imagem associada ao texto escrito enuncia uma ideia de educação. Assim, a imagem de pessoas de mãos dadas e o aspecto da coletividade pode ser interpretada como a educação enquanto responsabilidade de todos. Ao problematizar esse "todos", percebemos que a educação nessa perspectiva é responsabilidade de um "todos" exclusivamente privado. Isso porque em sua apresentação, o movimento não hesita em limitar-se a empresas do setor privado com atuação principal em outros setores, porém com diversos projetos que atuam diretamente na educação. Ainda na imagem, a pequena cidade apresentada ao fundo, evidencia o ideal educacional a ser alcançado: modelos pré-estabelecidos em outras nações, geralmente colonizadoras, sem considerar aspectos territoriais ou exitosos em outras nações do globo. 
Imagem 4. Imagem de abertura do site Movimento Colabora Educação.
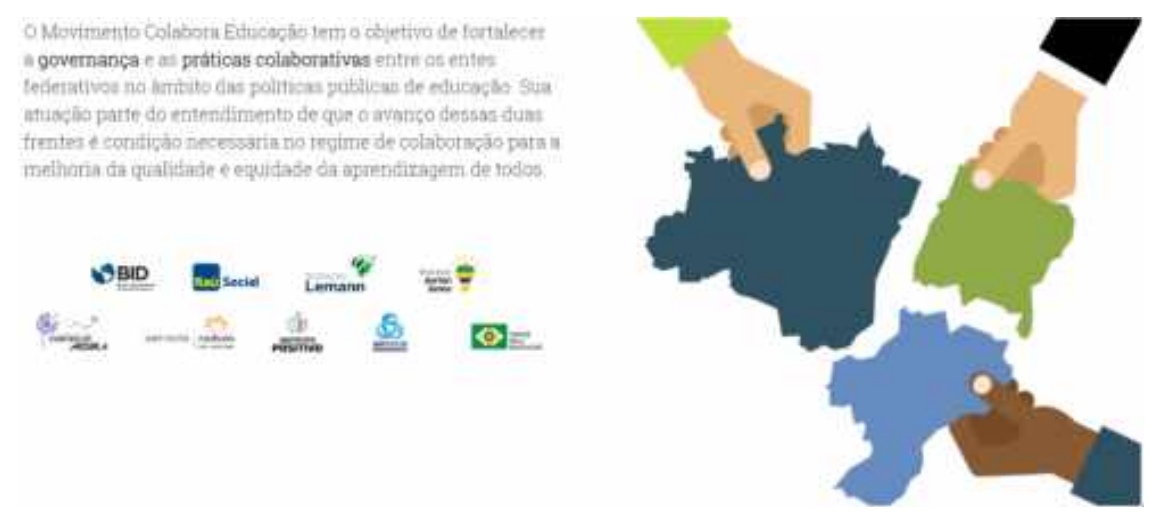

A construção da cenografia nos leva ao ethos. Observamos que o trecho "fortalecer a governança e as práticas colaborativas entre os entes federativos no âmbito das políticas públicas de educação" é parte importante para pensar aspectos da "benevolência" dessa iniciativa, por se tratar de membros-empresas que não são do setor educacional prioritariamente, mas que são bem-sucedidas em suas áreas de atuação, medindo esse sucesso através de sua lucratividade, e que atuam nesse setor implementando "boas práticas" empresariais na proposição de uma qualidade na educação brasileira.

Concluímos que o uso da palavra "fortalecer" tem valor fundamental e nos leva a compreensão de que precisa ser fortalecido o que está fragilizado. Assim, a atuação do setor público, supostamente fragilizada pelo mau funcionamento do Regime de Colaboração, é que precisa ser fortalecida. E é nesse sentido que o MCE justifica sua existência sob a qualidade de "lançar luz" sobre a coisa pública e o fazer do setor público supostamente na erradicação de uma educação desigual e de má qualidade.

Por fim, ao pensarmos a posição de sujeito, destacamos o co-enunciador (setor público) como esse sujeito limitado que não conseguiu dar conta da proposta inicial do Regime de Colaboração, necessitado dessa "ajuda" do setor privado que poderá auxiliar através de suas supostas bem-sucedidas práticas empresariais. Também o co-enunciador é burocrático, pois não facilita e até impede que a educação avance através dessa política. Já o enunciador (setor privado) é bem-sucedido, benevolente, técnico, empresarial e sua contribuição é fundamental para esse co-enunciador que, limitado, não poderá transformar a educação brasileira. O que observamos é uma construção discursiva que projeta sobre o setor público as limitações de alcançar qualidade através da iniciativa pública e que só o setor privado poderá "lançar luz sobre o entendimento da política educacional".

\section{CONSIDERAÇÕES SOBRE RESISTIR ÀS CONSTRUÇÕES DISCURSIVAS ENCANTADORAS}

A proposta de analisar o Movimento Colabora Educação surge a partir de uma palestra realizada em uma instituição pública de educação, na qual participamos e tivemos 
o primeiro contato com esse movimento. $\mathrm{O}$ despertar para a análise através das cenas de enunciação de Dominique Maingueneau foi possível diante da vivência em uma disciplina de Teoria e Análise do Discurso, no Programa de Pós-Graduação em Educação da Universidade Federal de Pernambuco (do qual fizemos parte enquanto estudantes de mestrado), em que nos foi proposta a construção de um texto analítico elegendo categorias da análise que estavam sendo estudadas.

A escolha pela a apresentação do MCE em seu site como corpus de análise foi material disponível e plausível dentro das possibilidades de construção do presente texto. Chamou-nos a atenção o material que estava sendo exposto na palestra e a forma como o representante do MCE expunha os argumentos para "vender" a atuação que o movimento possui. Já nos chamou atenção o nome: Movimento Colabora Educação, muito claro do lugar de atuação - política do Regime de Colaboração - e da construção discursiva do coenunciador e do enunciador - setor privado e setor público, respectivamente.

Na ausência de material da palestra, encontramos no site semelhança ao que estava sendo exposto na atividade e, assim, elegemos nosso corpus de análise. Ao longo da palestra ficamos estarrecidos com o encanto de algumas pessoas presentes que se identificaram como coordenadoras e professoras da rede estadual de ensino do Estado de Pernambuco. O encanto do discurso estava presente na palestra e identificamos que com esse intuito também o site é produzido. Imagens, objetividade, clareza e construção de um enunciador benevolente, contribuem para o encantamento com a iniciativa, sem criticidade e aceito passivamente.

Porém, analisar um discurso a partir das contribuições da Teoria e Análise do Discurso, especificamente as categorias propostas por Maingueneau, não nos possibilita analisar sem criticidade. Trata-se de perceber como as construções discursivas estão cheias de sentidos e atravessamentos. Significa perceber, também, que há possibilidades de ressignificações e resistências nessas construções. Apesar da sedução que a fala do palestrante envolvia significativa parte das pessoas na sala, uma das professoras pediu palavra e evidenciou em tom de revolta o que ali se desenhava, pois no seu entender, não era necessária essa atuação da iniciativa privada, mas sim, uma valorização e fortalecimento de setores públicos sobre projetos e políticas de educação.

Com suas palavras, interpretamos que: o que o palestrante vendia, ela não compraria, pois se tratava de uma construção discursiva em torno do papel do público e do privado sobre a educação. E aquela professora não aceitou a cena genérica passivamente, contestando as colocações do palestrante a partir de outras construções discursivas sobre a política do Regime de Colaboração. Assim, também, nós experimentamos analisar o site do MCE e identificar a construção discursiva não neutra e com interesses sobre a educação. 


\section{REFERÊNCIAS}

ABICALIL, Carlos Augusto. O Plano Nacional de Educação e o regime de colaboração na educação. REVISTA RETRATOS DA ESCOLA, Confederação Nacional dos Trabalhadores em Educação- CNTE, Brasília, p. 249-263, 2014.

ARGOLO, Juliana; MOTTA, Vânia. Arranjos de desenvolvimento da educação: regime de colaboração de 'novo' tipo como estratégia do capital para ressignificar a educação pública como direito. REVISTA UNIVERSIDADE E SOCIEDADE, Sindicato Nacional dos Docentes das Instituições de Ensino Superior-ANDES SN, São Paulo, p. 44-57, 2015.

BURITY, Joanildo. Discurso, política e sujeito na teoria da hegemonia de Ernesto Laclau. In: MENDONÇA, Daniel de.; RODRIGUES, Léo Peixoto. Pós-estruturalismo e teoria do discurso: em torno de Ernesto Laclau. 2. ed. Porto Alegre: EDIPUCRS, 2014. p. 59-74.

BUTLER, Judith. Fundamentos contingentes: o feminismo e a questão do pósmodernismo. CADERNOS PAGU, São Paulo, p. 11-42, 1998.

BRASIL. Emenda Constitucional $n^{\circ} 59$, de 11 de novembro de 2009. Acrescenta $\S 3^{\circ}$ ao art. 76 do Ato das Disposições Constitucionais Transitórias para reduzir, anualmente, a partir do exercício de 2009, o percentual da Desvinculação das Receitas da União incidente sobre os recursos destinados à manutenção e desenvolvimento do ensino de que trata o art. 212 da Constituição Federal, dá nova redação aos incisos I e VII do art. 208, de forma a prever a obrigatoriedade do ensino de quatro a dezessete anos e ampliar a abrangência dos programas suplementares para todas as etapas da educação básica, e dá nova redação ao $\S 4^{\circ}$ do art. 211 e ao $\S 3^{\circ}$ do art. 212 e ao caput do art. 214 , com a inserção neste dispositivo de inciso VI. Diário Oficial da União, Brasília, DF, 12 nov. 2009.

LACLAU, Ernesto. Discourse. In: GOODIN, Robert A.; PHILIP, Pettit (eds). A companion to conteporary political philosophy. Oxford: Blackwell, 1995. p. 431-437. LOPES, Alice; MACEDO, Elizabeth. Teorias de currículo. São Paulo: Cortez, 2011.

MAINGUENEAU, Dominique. Gênese dos Discursos. Trad. Sírio Possenti. São Paulo: Parábola, 2008.

MAINGUENEAU, Dominique. Análise de textos de comunicação. Tradução de Maria Cecília Souza-e-Silva e Décio Rocha. 6. ed. São Paulo: Cortez, 2013.

MAINGUENEAU, Dominique. Discurso e análise do discurso. Tradução de Sírio Possenti. 1. ed. São Paulo: Parábola Editorial, 2015.

MOVIMENTO COLABORA EDUCAÇÃO. Quem somos. [2018?]. Disponível em: $<$ http://movimentocolabora.org.br/quem-somos/>. Acesso em: 28 fev. 2019.

OLIVEIRA, G. Provocações para aguçar a imaginação/invenção analítica: aproximações entre a Teoria Política do Discurso e Análise do Discurso em Educação. In: LOPES; OLIVEIRA; OLIVEIRA. A teoria do discurso na pesquisa em educação. Recife: Editora UFPE, 2018.

PINTO, Flávio Sabino. Cena de enunciação, cena englobante e cena genérica: implicações nos estudos do discurso. REVISTA DE LETRAS NORTE@MENTOS, v. 8, n. 16, 2015.

SAVIANI, Dermeval. Plano Nacional de Educação, a questão federativa e os municípios: o Regime de Colaboração e as perspectivas da educação brasileira. GRABOIS, 2011. Disponível em: $<$ http://grabois.org.br/portal/revista.int.php?id_sessao $=16 \& i d \_p u b l i c a c a o=447 \& i d$ indi $\mathrm{ce}=2559>$. Acesso em: 25 fev. 2019. 
Artigo recebido em: set. de 2019.

Aprovado e revisado em: mar. de 2020.

Publicado em: julho de 2020.

Para citar este texto:

MELO, George Souza de; SILVA, Jéssica do Nascimento; SENA, Diego José de; SILVA, Erika Farias Nogueira da. "Lançando Luz sobre a Coisa Pública": uma análise do discurso do setor privado sobre o regime de colaboração. Entremeios [Revista de Estudos do Discurso, ISSN 21793514, on-line, www.entremeios.inf.br], Seção Estudos, Programa de Pós-Graduação em Ciências da Linguagem (PPGCL), Universidade do Vale do Sapucaí (UNIVÁS), Pouso Alegre (MG), vol. 21, p. 106-120, jan. - jun. 2020.

DOI: http://dx.doi.org/10.20337/ISSN2179-3514revistaENTREMEIOSvol21pagina106a120 